\title{
The "War" Concept in Russian and Chinese Socio-Cultural Environment
}

\author{
Oleg KALININ \\ Ph.D. (in Philology) \\ Lecturer \\ Department 40 (Far Eastern Languages) \\ Military University of the Ministry of Defense \\ Moscow, the Russian Federation \\ kallini4@yandex.ru

\section{Ruslan MAVLEEV} \\ Ph.D. (in Philology) \\ Senior Researcher \\ Military University of the Ministry of Defense \\ Moscow, the Russian Federation \\ rmavleev@gmail.com
}

\begin{abstract}
The main idea of the article is to analyze the concept of war in Russian and Chinese sociocultures, combining methods of linguo-cognitive and psycholinguistic approaches. The concept of war, on the one hand, is studied in terms of its linguistic manifestation with the help of cognitive-definitive analysis, and on the other hand, we attempt to examine the perception of this concept in the native speakers consciousness via psycholinguistic experiment. This technique allows us to consider the language manifestation of the studied concept, that is, to draw a conclusion about the linguistic worldview, and at the same time compare the main features of the "war" concept with the idea of a war in the minds of native speakers, that is, to draw a conclusion about the cognitive worldview. Studying the "war" concept allows us to fully understand the attitude of different peoples towards life, death and the principles of historical development. The study showed that the attitude of Russian and Chinese native speakers to the issues of war and peace is quite different: for Chinese culture, the dominant is materialistic consequences from the warfare and the image of the enemy, and for the Russian - the spiritual sufferings that war brings and the idea of the war as a craft.
\end{abstract}

Keywords: concept, conceptual analysis; psycholinguistic experiment; definition analysis; linguo- 
cognitive science.

\section{Introduction}

At present, cognitive language research is one of the most popular approaches to the study of culture and intercultural communication. The linguistic-cultural approach, based on the principle of "language to culture", consists of a detailed study of specific linguistic forms that reflect the conceptual areas that are important components of national linguistic culture, as well as an analysis of the relationship of these conceptual areas with scientific and cultural values and national mentality. This field of study is represented by a wide range of studies, in particular, Russian scientists Zalevskaya (2003), Karasik (2005), Vorkachev (2004), Slyshkin (2004), Sternin (2005) studied culture through the prism of linguocognitive studies. In addition, the works of Stepanov (2001) are widely known, as he was the one who as a result of large-scale linguistic and cultural studies created his own dictionary of Russian culture constants.

A separate line of research has emerged in Western science, commonly referred to as cognitive anthropology, which goes beyond traditional linguistics and explores a wide range of issues relating to cognitive sociology, political psychology and also behavioral economics.

Thus, one of the founders of this branch, D'Andrade (1995), pointed out: "Cognitive anthropology addresses the ways in which people conceive of and think about events and objects in the world. It provides a link between human thought processes and the physical and ideational aspects of culture".

At present, the focus of cognitive anthropology lies on how thought operations relate to signs and ideas (McGee, Warms, 2019; McGee, Warms. 2013) and on what determines the behavior of a person as a subject of a certain culture. At the same time, it is linguistic research methods and approaches that are the basis of cognitive anthropology to a large extent. The research of Ellis (2019), Fordham (2019), Goodenough (1981), Holland, Quinn (1998, 2018), Levinson (2003), Olásolo (2018), Poibeau (2018), Wassmann (2015), Zornado (2019) are widely known.

The approach being developed within the context of a cognitive approach to modeling culture deserves special attention. Sieck (2010), Rasmussen (2010, 2016), Duran (2016) and Smart (2010) have developed the Cultural Network Analysis, the essence of which is to perceive culture as a specific network of ideas that people transmit to each other within one cultural community. Naturally, one of the main forms of this network's existence is language and linguistic methods are the basis of CAN. 


\section{Research justification}

On the basis of the theoretical prerequisites for the study of a worldview as a cognitive-linguistic phenomenon, we are relying on the idea that there is a conceptual worldview as a set of formed group (national, professional-group, social, gender) and individual concepts and a language worldview, the reflection of which is the language worldview. In this context, we in many ways agree with the researchers from Culture \& Cognition Group, who, as we have written above, see the culture as a "network of interconnected ideas" (Sieck, Rasmussen, Jasmine, 2016; Sieck, 2010; Sieck, Rasmussen, Smart, 2010; Sieck, Rasmussen, Duran, 2016).

Basic methods of linguistic cognitive research in the cultural paradigm will be used in this research. In terms of terminology, we will stay within the tradition of Russian linguocognitive research and, in order to avoid misunderstanding, we will use the term concept in the meaning of "a unit of knowledge and meaning that a person operates in the process of thinking" (Boldyrev, 2014).

Avoiding the disputes about the meaning of this term, we will notice that in the majority of the publications studying certain concepts are mainly focused on the study of the linguistic shell of a concept, i.e. those lexical units which, in the opinion of a certain researcher, are reflected in the language. We offer a deeper approach to the analysis of a concept not only as a linguistic phenomenon, but also as a phenomenon of speech and psychology.

In other words, we believe that the essence of the basic concepts as "clots of meaning" is more or less manifested both in the language as a whole and in the speech of every native speaker. The basis for the research of thematic concepts of the national worldview is usually the national language as it's fixed in dictionaries. However, the meaning of the concepts as fixed in dictionaries can be and should be clarified by analyzing the meaning of the concept with the help of analyzing the consciousness and speech factors of speakers belonging to a certain linguoculture.

The tripartite approach to the study of a concept as a linguistic, speech and psychological phenomenon is the novelty of this work.

This research represents some results of testing the method of tripartite comparative analysis of the thematic concept as a component of the national worldview. In this article we will mainly dwell on two of the three components of the war concept, on the linguistic and psychological ones, and that has determined the method of research described below.

Thus, the object of this research can be defined as linguistic, psychological and cognitive components of the thematic concept, and the subject of the research - the concept of war in the Russian and Chinese linguocultures. 
The authors will provide a number of introductory explaining remarks about the choice of the subject of the study. War as a special specific type of human activity has existed throughout the human history. In addition, the results of scientific research converge on the thesis of "struggle for existence" as the basis of evolution. In this regard, it seems reasonable to assume that the idea of armed struggle for the possession of some benefits, which can be called "war" and which in many ways reflects the fundamental concepts of good and evil, life and death, and the national character, which is called mentality, is formed on this basis. No doubt, war is not the only indicator of the national worldview, but, nevertheless, the study of this aspect of life is considered to be very revealing. Especially interesting is the analysis of the concept of war in the context of Russian and Chinese cultures, as the historical experience of the nations shows a different approach not only to the methods and techniques of warfare, but also to the very essence of war as a form of activity.

The aim of the study is be to make a comparative substantial analysis of the concept of war in Russian and Chinese linguocultures from the linguistic and psychological point of view.

Theoretical value of the research is a partial approximation of the new method of analysis of the concept as a component of the national worldview, which includes the study of several manifestations of the concept, in particular, the identification of the linguistic and psychological components of the thematic concepts using certain methods of linguocognition and psycholinguistics.

Besides, an intensive study of the concept of war in a comparative way for the Chinese and Russian linguocultures will allow to better understand the features of the national character of the two nations.

\section{Methods}

Based on the abovementioned theoretical prerequisites as well as the relevance of the object and subject of study, the authors define the research methodology as a two-step analysis based on particular methods typical for linguocognitive science and psycholinguistics:

1. Conceptual and definitive analysis:

1.1 Dictionary analysis of word definitions aimed at identifying essential conceptual characteristics

1.2 Analysis of the origin of the conceptual word-representant in order to identify motivational etymological characteristics.

This is the most basic method of linguocognitive research, which allows quickly and accurately 
record the main nominative characteristics of the concept, formulate its core and to form an understanding of the periphery. The conceptual and definitive analysis is a kind of "express test", the results of which, although they are of a simplified nature, differ from each other in a rather significant reliability.

\section{Psycholinguistic experiment}

The essence of the experiment was the associative experiment, which is rightly considered one of the most effective methods of studying typical manifestations of national and cultural specifics in the linguistic consciousness of an individual. Being spread over a social group, the linguisticassociative experiment made it possible to reveal stereotypical semantic links in the mentality of the people.

The essence of the experiment consisted in revealing the most significant characteristics of the concept of war in the consciousness of speakers of a certain linguistic culture. The experiment was based on a simple survey conducted through social networks using Google Forms technology. In our research 80 respondents for each linguoculture took part, and 20 of them were personnel soldiers. From a technical perspective, respondents were asked the question, "What is war?" and respondents were asked to answer as briefly as possible, using one word or phrase.

The methodology of this research is quite simple, and it is in this simplicity that its reliability lies. The effectiveness and reliability of these methods is beyond doubt, and therefore the results obtained are also highly reliable.

\section{Results}

The first stage of the research was the conceptual-definitive analysis of the cognitive field of war in Russian and Chinese linguocultures.

Here are the main definitions of the word-representant for the concept of war in the Russian language:

- an organized armed struggle between two or more parties, usually States, nations (peoples), social groups, usually for political or economic purposes;

- a complex social phenomenon, usually the continuation of the political struggle of States, nations, classes by means of armed violence, which mainly represent different forms of organized armed struggle (Dictionary of military terms);

- a social and political phenomenon, which is an extreme form of resolving social and political, economic, ideological, as well as national, religious, territorial and other contradictions between 
States, peoples, nations, classes and social groups by means of military force (Dictionary of emergency situations terms);

- a social and political phenomenon, continuation of policy using violent means (Soviet Historical Encyclopedia).

From the etymological point of view, "war" in Russian has a Slavic origin and variations of words with the same meaning are found in almost all Slavic languages. It is also related to the Latin word "venari” and to the Old German word "weida” - "hunting".

According to the above vocabulary definitions, we can conclude that the basic meaning of the conceptual field of the word "war" in the Russian language is a "form of armed struggle" defined by socio-political factors. At the same time, the understanding of war as a "social phenomenon closely related to the state politics" is also very significant.

Below are the main definitions of the word-representant for the concept of war in Chinese:

- 斗争矛盾表现的最高形式 the highest form of struggle and contradiction (The Big Dictionary of Chinese Hieroglyphs).

- 一种集体、集团、组织、民族、派别、国家、政府互相使用暴力、攻击、杀翏等行为, 使敌对双方为了达到一定的政治、经济、领土的完整性等目的而进行的武装战斗 -actions in which groups of people, nations, states and governments use armed violence to gain certain political, economic or territorial benefits (The Big Dictionary of Chinese Hieroglyphs);

- 为政治目的而进行的武装斗争 - armed struggle for political purposes (Xinhua on-line Dictionary);

Due to the typological peculiarities of the Chinese language, the conceptual-definition analysis should also include a review of the semantics and structural features of each character that makes up the word-representant.

战 zhàn - 1) war; battle, struggle; 2) competition, wrestling; sports competition; game (挑战 - call for competition, 冷战 - cold war) (The Big Chinese-Russian Dictionary).

From the structure and origin point of view the character 战 consists of two parts, namely graphemes: 占 - to capture and 戈 - a ticker, i.e. 战 is an armed capture.

争 zhēng - 1) to fight, fight for something, win; 2) to compete; 3) to argue, discuss (争权- to fight for power, 争功- to challenge each other's merits). 
In terms of structure and origin the character 争 consists of two graphemes: 刀- a blade and $\exists$ - a pig's head, that is 争 - is an armed clash for a pig, that is an armed clash for food (The Big ChineseRussian Dictionary).

As a result of conceptual-definitive and etymological analysis of the word-representant of the conceptual field of the word "war" in the Chinese linguoculture, we see that war is also a "form of armed struggle". At the same time, it is extremely important to indicate that the war is conducted for the purpose of obtaining benefits. Probably this explains the presence of the sign 占 "capture" in the root character to indicate the concept of war 战.

Thus, the above analysis shows that in Russian and Chinese linguocultures war is perceived in many ways similarly, namely, as a "form of armed struggle associated with politics. However, there are some serious differences as well:

- In addition to the above-mentioned meanings, Russian linguoculture also treats war as a "social phenomenon", which indicates that the state of war for the Russian people is natural in some way.

- In Chinese linguoculture, the semantic meaning of "struggle to achieve something, to obtain some benefits" is very significant, which is manifested not only in the vocabulary, but also etymologically through the characters.

The second stage of the analysis of the concept of war in Russian and Chinese linguocultures is a psycholinguistic experiment.

The most frequent answers in the survey for the speakers of the Russian linguoculture were: death, blood, suffering, grief, tears, violence, misfortune, murder, disaster, destruction, fear, horror, pain, chaos, cruelty, weapon/army.

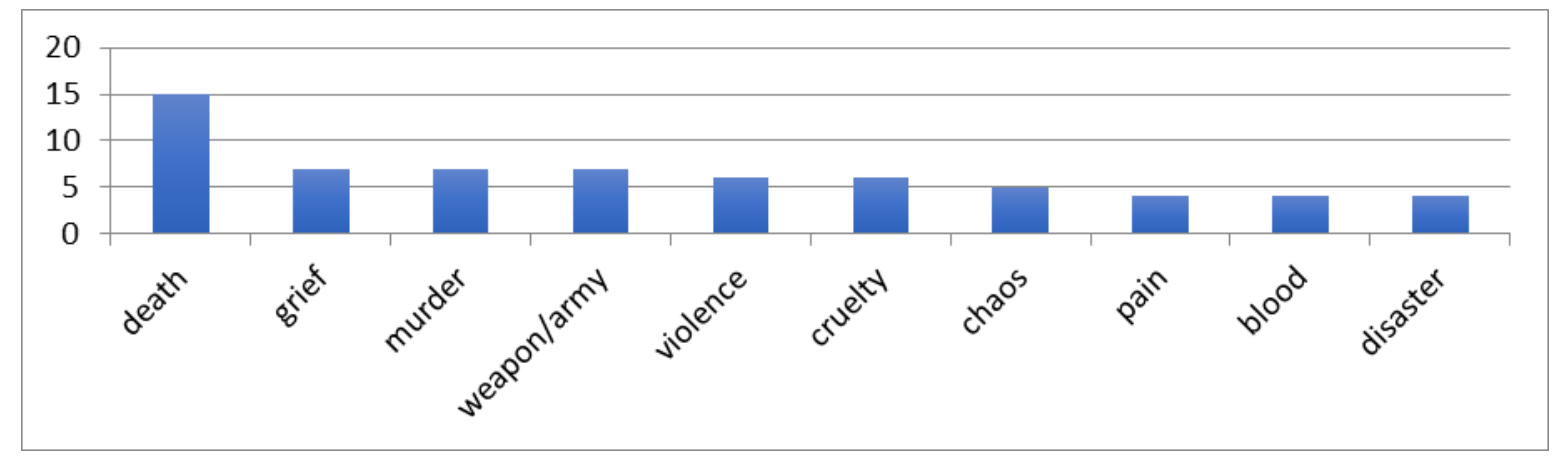

Figure 1. Answers of the speakers of the Russian linguoculture

The analysis of the answers of the Russian respondents allowed to reveal the following component 
values of the conceptual field of the word "war":

1) Death (15), violence (6), murder (7): cruelty (6), blood (4)), a total of 38 references per group;

2) State of mind (grief (7), suffering (3), pain (4), tears (2), fear (2), misfortune (3), horror (3)), a total of 24 references per group;

3) Consequences (chaos (5), disaster (4), destruction (2)), a total of 11 references per group;

4) Weapons (represented by lexeme: weapons (7)) - a total of seven references per group.

The most frequent answers for the Chinese respondents were: death, to die, suffering, fear, blood, Japan, cruelty, disaster, horror, disorder, enemy, violence, pain.

Let's present the data as a table for better illustration.

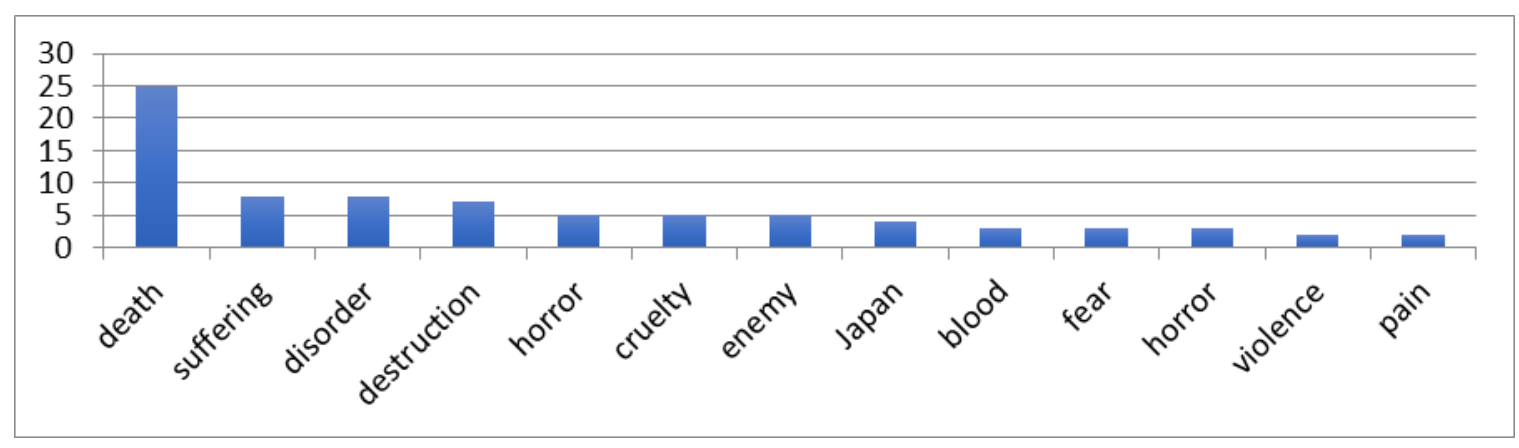

Figure 2. Answers of the speakers of the Chinese linguoculture

The analysis of the answers of the Chinese respondents made it possible to reveal the following component values of the conceptual field of the word "war":

1) Death (represented by the lexemes: death (25), violence (2), cruelty (5), blood (3)), a total of 35 references per group;

2) State of mind (represented by the thematic group of nouns: suffering (8), pain (2), fear (3), horror (3)), a total of 16 references per group;

3) Consequences (represented by a group of lexemes: disorder (8), disaster (4), destruction (7)), a total of 19 references per group;

4) Enemy (represented by the lexemes: Enemy (5), Japan (4)). - a total of 9 references per group.

The division into groups by component value of the substance of the word "war" and its conceptual field for the groups of Chinese and Russian respondents has some similarities and differences, 
which are presented in the table below.

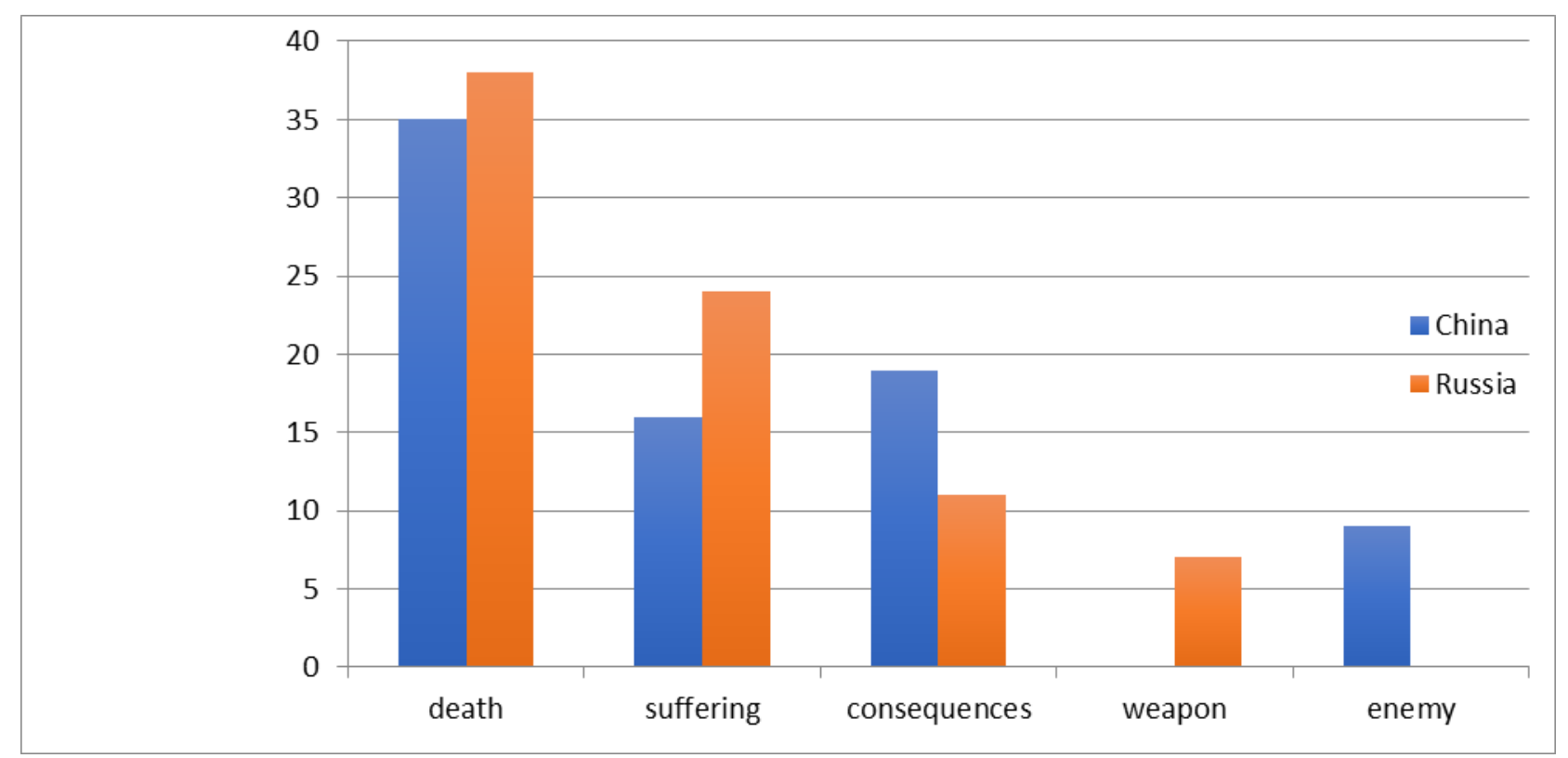

Figure 3. Comparison of the component values of the cognitive constituent of the war concept in Russian and Chinese linguocultures

\section{Discussion}

Comparative analysis shows that the concept of war in Russian and Chinese linguocultures has both similarities and differences.

1) In both linguocultures, the "death" component has become the determining one, which is not a surprise given the historical development of Russia and China through numerous military conflicts. It is worth mentioning that the lexemes included in this component group are almost identical for both languages. This shows that the speakers of both linguocultures perceive war as "cause of death" and "source of violence".

2) The component group "Suffering" was significant for the Russian-speaking respondents, while the component group "Consequences" was important for the Chinese respondents. This is probably related to the historical memory of the peoples of Russia, in which the tragic consequences of the Great Patriotic War affected nearly every family, and these consequences were mainly related to the loss of loved ones and relatives, which is reflected in the semantic field of "Suffering" as a part of the concept of war. From the Chinese point of view, the death of one particular person is not always a tragedy, which is typical for Asian cultures. While harmony and order are the features of the Chinese spiritual tradition, war obviously becomes the main cause of the natural course of events. 
It should be noted that the lexical units of the component groups "Suffering" and "Consequences" are partially similar semantically, but the group "Suffering" is more represented by lexemes associated with spiritual experiences and consequences, while the group "Consequences" associated with material destruction and disorder in society. This difference characterizes Russian linguoculture is "inner-oriented", i.e. aimed at empathizing the grief of each individual, and Chinese linguoculture is "outer-oriented", i.e. aimed at maintaining order and harmony in society as a whole. Russians perceive the disasters of war through personal tragedy, while Chinese culture pays more attention to the devastating effects of war on the state and society.

3) The presence of lexical units belonging to the component group "Weapon" in the answers of the Russian respondents indicates that the representatives of Russian culture perceive war as a craft, a certain type of professional activity.

4) In the answers of the Chinese respondents we were able to distinguish the component group "Enemy", which may indicate a tendency to identify the war with a specific enemy, the presence of the lexeme "Japan" indicates the personalization of the enemy.

The analysis of the conceptual field of warfare in Chinese and Russian linguocultures, carried out by means of conceptual-definitive analysis and a survey of native speakers, allows us to say that despite the similarity of the understanding of what is war, the understanding of war differs quite strongly, which reflects both at the level of semantics and etymology of the word-representant itself, and also in the results of the associative experiment.

Table 1. Comparative characteristics of the conceptual field of war in Russian and Chinese linguocultures

\begin{tabular}{ccc} 
& Russian linguoculture & Chinese linguoculture \\
\hline Basic meaning according to \\
dictionary & Form of armed struggle & Form of armed struggle \\
\hline Secondary dictionary meaning & & \\
\hline Etymology & Type of political activity & Activities aimed at generating \\
& & economic benefits \\
\hline «Death» component & Armed struggle & Struggle for benefits \\
\hline «Suffering» component & dominant & secondary
\end{tabular}




\section{Conclusion}

The method of tripartite analysis of the concept as a linguistic, speech and psychological phenomenon can be and should be supplemented by new empirical research in a comparative way. The study of the concept "here and now", showing its concrete outlines in the minds of the speakers of some linguistic culture, can become an effective way of studying the national psychology. In addition, the consistent conduct of such studies over a certain period of time, especially in connection with current foreign policy events, may become the basic method for understanding the factors of change and evolution of the national consciousness of a certain linguoculture.

The results of our research of the linguistic and psychological component of the war concept in the Russian and Chinese linguocultures not only demonstrate the differences in understanding of the phenomenon of war between the two nations, but also show that the study of the concept by means of associative experiment, deepens the understanding of the substance of thematic linguistic concepts.

\section{References}

Boldyrev, N.N. (2014). Cognitive Semantics. Introduction into the Cognitive Linguistics: lecture course. Tambov: Publishing house of TGU n.a. G.R. Derzhavin.

D'Andrade, R. (1995). The Development of Cognitive Anthropology. New York: Cambridge University Press.

Dictionary of emergency situations terms. Retrieved from: https://rus-emergencyterms.slovaronline.com (Accessed on October 18, 2019)

Dictionary of military terms. Retrieved from: https://slovaronline.com/search?s=war (Accessed on October 18, 2019)

Ellis, N. (2019). Essentials of a Theory of Language Cognition. Modern Language Journal, 103, 39-60.

Fordham, F. (2019). Mapping Cultural Networks and its Discontents. Gaziantep Üniversitesi Sosyal Bilimler Dergisi, 1, 1-15.

Goodenough, W. (1981). Culture, Language and Society. New York: Addison-Wesley.

Karasik, V.I., Sternin, I.A. (2005). Anthology of Concepts, 1-2. Volgograd: Paradigm. 
Levinson, S. (2003). Space in Language and Cognition: Explorations in Cognitive Diversity. Cambridge: Cambridge University Press.

McGee, R., Warms, R. (2013). Theory in Social and Cultural Anthropology: An Encyclopedia. London: SAGE Publications.

McGee, R., Warms, R. (2019). Anthropological Theory: An Introductory History. New York: Rowman \& Littlefield Publisher.

Olásolo, H. (2018). Ten Lectures on Language, Cognition, and Language Acquisition (Distinguished Lectures in Cognitive Linguistics). Leiden: BRILL.

Poibeau, T. (2018). Language, Cognition, and Computational Models. Cambridge: Cambridge University Press.

Quinn, N. (1998). A Cognitive Theory of Cultural Meaning (Publications of the Society for Psychological Anthropology). Cambridge: Cambridge University Press.

Quinn, N. (2018). Advances in Culture Theory from Psychological Anthropology (Culture, Mind, and Society). London: Palgrave Macmillan.

Sieck, W. (2010). Cultural network analysis: Method and application. Advances in Cross-Cultural Decision Making, 260-269.

Sieck, W., Rasmussen, L., Duran, J. (2016). Considerations and best practices for developing cultural competency models in applied work domains. Critical Issues in Cross Cultural Management, 33-52.

Sieck, W., Rasmussen, L., Jasmine, L. (2016). Considerations and Best Practices for Developing Cultural Competency Models in Applied Work Domains. Critical Issues in Cross Cultural Management, 33-52.

Sieck, W., Rasmussen, L., Smart, P. (2010). Cultural Network Analysis: A Cognitive Approach to Cultural Modeling. Network Science for Military Coalition Operations: Information Extraction and Interaction, 146-163.

Slyshkin, G.G. (2004). Linguocultural Concepts and Metaconcepts. Volgograd: Peremena.

Soviet Historical Encyclopedia. Retrieved from: https://gufo.me/dict/history_encyclopedia (Accessed on October 18, 2019)

Stepanov, Y.S. (2001). Constants. Dictionary of Russian Culture. Moscow: Academic project. 
Sternin, I.A. (2018). Study of Meaning as a Phenomenon of Linguistic Consciousness. Monograph. Almaty: Polilingva.

The Big Chinese-Russian Dictionary. Retrieved from: http://bkrs.info (Accessed on October 18, 2019)

The Big Dictionary of Chinese Hieroglyphs. Retrieved from: http://www.hydcd.com (Accessed on October 18, 2019)

Vorkachev, S.G. (2004). Happiness as a Linguocultural Concept. Moscow: Gnozis.

Wassmann, J., Bender, A. (2015). Cognitive Anthropology. International Encyclopedia of the Social \& Behavioral Sciences. Amsterdam: Elsevier, 16-22.

Xinhua on-line Dictionary. Retrieved from: http://xh.5156edu.com (Accessed on October 18, 2019)

Zalevskaya, A.A. (2003). Linguistic Consciousness: Questions of Theory. Questions of Psycholinguistics Journal, 1, 30-35.

Zornado, J., Harrison, J., Weisman, D. (2019). Cultural cognition. Critical Thinking. Philadelphia: Routledge. 